\title{
Pathophysiology of nasal congestion
}

This article was published in the following Dove Press journal:

International Journal of General Medicine

15 February 2010

Number of times this article has been viewed

\author{
Robert M Naclerio' \\ Claus Bachert ${ }^{2}$ \\ James $\mathrm{N}$ Baraniuk $^{3}$ \\ 'University of Chicago, \\ Department of Surgery, Section \\ of Otolaryngology - Head and \\ Neck Surgery, Chicago, Illinois, USA; \\ ${ }^{2}$ University of Ghent, Ghent, Belgium; \\ ${ }^{3}$ Georgetown University, Washington, \\ DC, USA
}

Correspondence: Robert M Naclerio

University of Chicago, MC 1035,

584 I S. Maryland Avenue, Chicago,

IL 60637, USA

$\mathrm{Tel}+\mathrm{I} 773-702-1865$

Fax +I 773-702-98I3

Email rnacleri@surgery.bsd.uchicago.edu

\begin{abstract}
Nasal congestion is a common symptom in rhinitis (both allergic and nonallergic), rhinosinusitis and nasal polyposis. Congestion can also be caused by physical obstruction of nasal passages and/or modulation of sensory perception. Mucosal inflammation underlies many of the specific and interrelated factors that contribute to nasal congestion, as well as other symptoms of both allergic rhinitis and rhinosinusitis. A wide range of biologically active agents (eg, histamine, tumor necrosis factor- $\alpha$, interleukins, cell adhesion molecules) and cell types contribute to inflammation, which can manifest as venous engorgement, increased nasal secretions and tissue swelling/edema, ultimately leading to impaired airflow and the sensation of nasal congestion. Inflammation-induced changes in the properties of sensory afferents (eg, expression of peptides and receptors) that innervate the nose can also contribute to altered sensory perception, which may result in a subjective feeling of congestion. Increased understanding of the mechanisms underlying inflammation can facilitate improved treatment selection and the development of new therapies for congestion.
\end{abstract}

Keywords: allergic rhinitis, congestion, obstruction, pathophysiology, rhinosinusitis

\section{Introduction}

Nasal congestion or obstruction is one of the most frequent symptoms encountered in primary care and specialist clinics, and it is often the predominant symptom in upper respiratory tract disorders, such as allergic rhinitis, rhinosinusitis, nonallergic rhinitis, and nasal polyposis. Additionally, nasal congestion is also a common symptom in otitis media and asthma, and it can contribute to the onset or worsening of sleep disturbances, including obstructive sleep apnea. ${ }^{1}$

The pathophysiology of nasal congestion, which may be best described as a perception of reduced nasal airflow or a sense of facial fullness, involves a number of underlying mechanisms. These include mucosal inflammation, often involving increased venous engorgement, increased nasal secretions, and tissue swelling/edema; physical problems affecting the structure of the nasal passage; and/or modulation of sensory perception. Many inflammatory and neurogenic mediators contribute to plasma exudation and vasodilatation, with resultant edema and swelling of the nasal mucosa. Various technological advancements including rhinomanometry and acoustic rhinometry, offer complementary tools to qualitatively and quantitatively study the nasal airway, providing greater insight into the physiological fluctuations and pathophysiological mechanisms that influence nasal patency. ${ }^{2,3}$

The purpose of this article is to review the various pathophysiological mechanisms that contribute to objective nasal congestion or the perception of nasal congestion.

submit your manuscript | www.dovepress.con 


\section{Mucosal inflammation}

Mucosal inflammation is the central pathophysiological mechanism that underlies many of the specific and interrelated factors that contribute to congestion, including increased venous engorgement, increased nasal secretions and tissue swelling/edema. ${ }^{4}$ In the following sections, we will provide examples of parts of the inflammatory process, rather than encyclopedic coverage of the pathophysiological processes associated with each disease.

Inflammation associated with allergic rhinitis and rhinosinusitis can reduce the physical size of the nasal passages by inducing vasodilatation, increasing blood flow and increasing vascular permeability. The result is engorgement of nasal venous sinusoids, swelling of the anterior and inferior turbinates and obstruction of nasal airflow, ultimately contributing to nasal congestion. ${ }^{5}$ In addition, some patients are unable to adequately control sinusoid venous engorgement, which may be due to conditions such as Horner's syndrome, nasal reflex sympathetic dystrophy, rhinitis medicamentosa, and treatment with $\alpha$-adrenergic antagonists. ${ }^{6-8}$ More frequently, however, sinonasal venous engorgement and inflammation are associated with common upper respiratory tract disorders, such as allergic rhinitis and rhinosinusitis.

\section{Allergic rhinitis}

The prevalence of allergic rhinitis is increasing worldwide, occurring in $10 \%$ to $30 \%$ of adults and up to $45 \%$ of children. ${ }^{9-11}$ Nearly $50 \%$ of patients with allergic rhinitis experience symptoms for $>4$ months of the year, and nasal congestion is frequently the predominant symptom. Other symptoms of allergic rhinitis include nasal itching, rhinorrhea, and sneezing, as well as ocular itching, redness, and tearing. ${ }^{12}$

Although inflammation and tissue swelling/edema are frequent components of other common upper respiratory tract disorders, such as rhinosinusitis, the underlying inflammatory mechanisms have been primarily studied in the setting of allergic rhinitis. Symptoms of allergic rhinitis, including nasal congestion, are primarily due to a combination of the early and late-phase allergic inflammatory response. ${ }^{13-18}$ In a sensitized host, an antigen comes into contact with the nasal mucosa, leading to crosslinking of immunoglobulin $\mathrm{E}$ (IgE) receptors on mast cells. This results in degranulation of these cells and the release of histamine and proteases from preformed granules. ${ }^{13-15}$ In addition, an array of early-phase proinflammatory molecules are synthesized and released, most notably leukotrienes, prostaglandins, tumor necrosis factor (TNF)- $\alpha$, and interleukin (IL)-4. ${ }^{13,19,20}$ Release of these inflammatory mediators leads to swelling/edema and fluid secretion, resulting in congestion as well as other nasal symptoms. ${ }^{19}$

A large body of literature supports a role for leukotrienes as mediators in allergic rhinitis. Cysteinyl leukotrienes can be recovered in nasal secretions after exposure to natural allergen $\mathrm{s}^{21}$ and at elevated concentrations in allergic rhinitis with increased allergen dose exposure (Figure 1a). ${ }^{22}$ Challenge with cysteinyl leukotriene also increases nasal airway resistance (Figure 1b). ${ }^{23}$ In addition, cysteinyl leukotrienes may facilitate the maturation of eosinophil precursors and act as eosinophil chemoattractants, promoters of eosinophil adhesion, and inhibitors of eosinophil apoptosis. ${ }^{20}$

Like leukotrienes, thromboxanes are arachidonic acid derivatives, released from mast cells and other inflammatory cells, that are found in nasal lavage fluid samples following nasal allergen challenge. ${ }^{24,25}$ In animal models, TXA2 agonists increase nasal airway resistance and vascular permeability. ${ }^{25}$ TXA2 receptor antagonists have also been shown to improve congestion in animals and reduce nasal mucosal swelling in AR patients following allergen challenge..$^{24,25}$

Prostaglandin $\mathrm{D}_{2}\left(\mathrm{PGD}_{2}\right)$ is the major prostanoid produced in the acute phase of allergic reactions, and it is thought to be associated with hypertrophic inflammation in the nose and recruitment of eosinophils. ${ }^{26} \mathrm{~A}$ number of other biomarkers of inflammation, including tryptase, $\mathrm{N}$-alpha-tosyl L-arginine methyl ester (TAME)-esterase and eosinophil cationic protein (ECP), are also detectable in the nasal mucosa within minutes to hours after allergen challenge. These mediators stimulate the early phase response and also lead to increased venous engorgement, which results in concomitant rhinorrhea and nasal congestion. ${ }^{19}$

The chronic, late-phase inflammatory response involves cellular infiltration, which sustains tissue swelling and edema, further exacerbating congestion. ${ }^{13-15}$ As a result of cytokine or mediator release, the nasal mucosa becomes infiltrated with inflammatory cells including eosinophils, neutrophils, basophils, mast cells, and lymphocytes, that sustain and exacerbate the nasal mucosal inflammatory reaction. ${ }^{20}$

Eosinophils are the predominant cell type in the chronic inflammatory processes that characterize the late-phase allergic response, and they release a broad array of proinflammatory mediators, including cysteinyl leukotrienes, ECP, eosinophil peroxidase, and major basic protein. ${ }^{15,20}$ These cells may also serve as a major source of IL-3, IL-5, granulocyte-macrophage colony-stimulating factor (GM-CSF), and IL-13. ${ }^{20} \mathrm{IL}-5$ is an eosinopoietic cytokine that promotes eosinophil differentiation and maturation within 


\section{A}

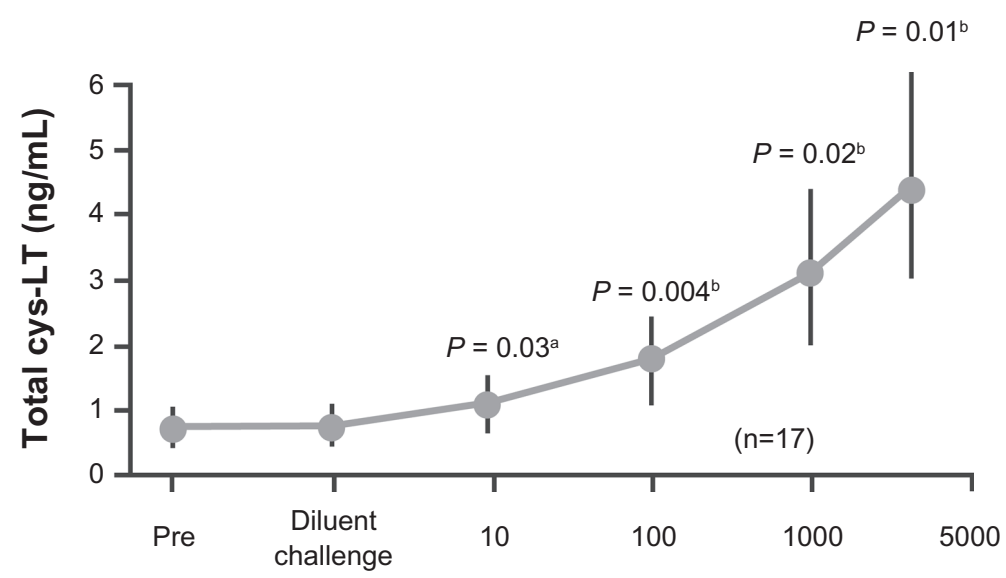

Ragweed pollen grains/challenge dose

B

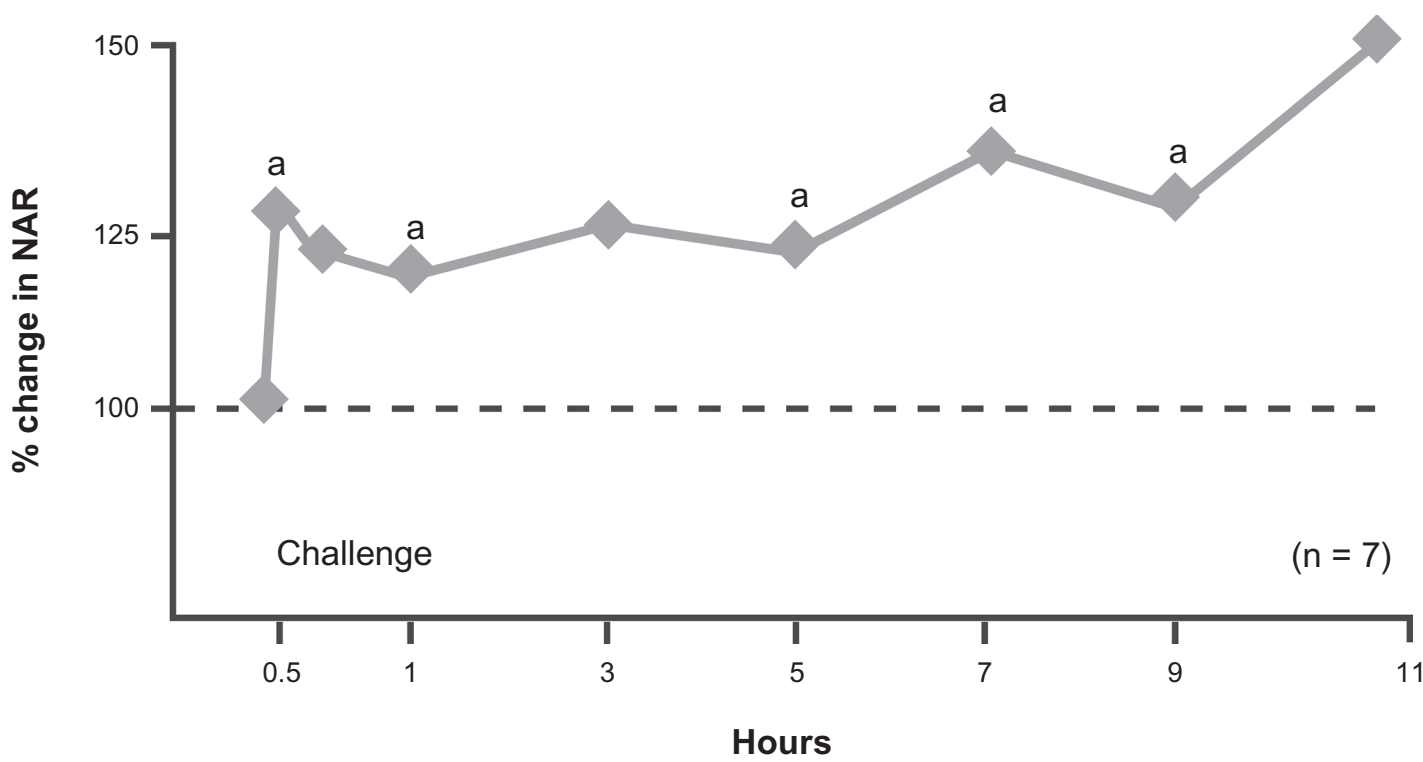

Figure I Clinical data support a role for leukotrienes as mediators of congestion in allergic rhinitis. A) Cysteinyl leukotrienes (cys-LT) can be recovered at elevated levels in nasal secretions with increased allergen dose exposure in patients with allergic rhinitis. ${ }^{2}$ Versus baseline. ${ }^{\text {b } V e r s u s ~ p r e v i o u s ~ p o l l e n ~ d o s e ~ a n d ~ b a s e l i n e . ~ A d a p t e d ~ w i t h ~ p e r m i s s i o n ~}$ from Creticos PS, Peters SP, Adkinson NF Jr, Naclerio RM, Hayes EC, Norman PS. Peptide leukotriene release after antigen challenge in patients sensitive to ragweed. N EngI J Med. 1984;310(25):1626-1630. ${ }^{22}$ Copyright (C 1984 Massachusetts Medical Society. All rights reserved. B) Challenge with cysteinyl leukotriene increases nasal airway resistance (NAR). ${ }^{a} P<0.05$ vs baseline. Adapted with permission from Okuda M,Watase T, Mezawa A, Liu CM. The role of leukotriene D4 in allergic rhinitis. Ann Allergy. I 988;60(6):537-540. ${ }^{23}$ Copyright (C) 1988 American College of Allergy, Asthma and Immunology.

the bone marrow. ${ }^{27}$ Circulating eosinophils are increased in number in subjects with allergic disorders, and infiltration at the site of provocation has been generally attributed to influx of mature cells. However, there appears to be a subset of eosinophil progenitor cells that undergo local maturation in the nasal mucosa, also in an IL-5-dependent fashion. ${ }^{27}$ Eosinophil infiltration has been demonstrated to have a significantly negative correlation with nasal airflow in patients with allergic rhinitis. ${ }^{28}$ The cellular infiltration of the late-phase response also primes the mucosa for additional antigen exposure and increases the response to it, thus further exacerbating symptoms upon continued exposure (eg, as the allergy season progresses). ${ }^{29}$

In addition to eosinophils, other inflammatory cells, eg, basophils, mast cells, T cells, also accumulate within the nasal epithelium during the late-stage response. ${ }^{13,15}$ Leukocyte activation, with subsequent migration to sites of inflammation, leads to changes in the cell membrane (eg, increased integrin expression) that result in adhesion to the endothelial surface. ${ }^{30}$ Survival of cells that have been recruited and 
migrated to sites of inflammation, particularly eosinophils and mast cells, is enhanced by epithelial generation of GM-CSF, IL-5, and stem cell factor (SCF). ${ }^{30,31}$ Cultured nasal epithelial cells have been shown to generate SCF in vitro, and levels of this growth factor are increased in nasal lavage fluids from patients with seasonal allergic rhinitis. ${ }^{30}$

TNF- $\alpha$ is a key inflammatory mediator of the late-phase response, and its levels have been shown to be dramatically increased beginning at about 1 hour after allergen challenge. ${ }^{19}$ Plasma exudation and preferential upregulation of neutrophils over eosinophils during the late phase are characteristic of the response to TNF- $\alpha .{ }^{32}$ This cytokine has been demonstrated to activate $\mathrm{T}$ cells, endothelial cells, fibroblasts, and macrophages to express cell surface receptors and to release additional inflammatory cytokines. ${ }^{13,14,19} \mathrm{TNF}-\alpha$ also increases the expression of cell adhesion molecules (intercellular adhesion molecule 1 [ICAM-1] and vascular cell adhesion molecule 1 [VCAM-1]). ${ }^{19}$ Proinflammatory interleukins (IL-1 $\beta$, IL-6, and IL-8) are elevated in patients with allergic rhinitis and have been shown to promote the activation of immune cells as well as to enhance expression of receptors for cell adhesion molecules (eg, selectins, integrins). ${ }^{19}$ These events, along with IgE synthesis and eosinophil/basophil priming, collectively contribute to inflammation, venous engorgement, nasal hyperreactivity, and symptoms of allergic rhinitis, including congestion. ${ }^{19,33}$

Nonallergic rhinitis (that which is not mediated by an $\mathrm{IgE}$ response) includes infectious rhinitis, vasomotor rhinitis, nonallergic rhinitis with eosinophilia syndrome (NARES), and hormonal rhinitis (that precipitated by pregnancy and menstrual irregularities). In particular, significant nasal congestion may be present with pregnancy-related rhinitis. $^{34}$

\section{Rhinosinusitis}

Rhinosinusitis is now the accepted term for a group of disorders characterized by inflammation of the mucosa of the nasal passages and paranasal sinuses. Although the term itself is specific, rhinosinusitis may be due to an array of etiologic agents, including microorganisms; noninfectious, nonimmunologic causes; and allergic and nonallergic immunologic inflammation. ${ }^{34,35}$

The most common cause of rhinosinusitis is viral infection (often referred to as the common cold). ${ }^{36} \mathrm{~A}$ large body of research supports the view that symptoms of the common cold are not due to direct cytopathic effects of the viral infection. Rather, it appears that viral infection stimulates inflammatory pathways that, once activated, tend to prolong symptoms even after viral replication has been ablated. ${ }^{37}$ In addition, an estimated $0.5 \%$ to $2 \%$ of cases of viral rhinosinusitis are complicated by secondary bacterial infections. ${ }^{35}$

Regardless of etiology, rhinosinusitis is typically classified as acute or chronic, depending on duration of symptoms. ${ }^{38}$ Although microorganisms play a predominant role in the etiology of acute rhinosinusitis, the role of infection in patients with chronic rhinosinusitis is controversial (although in a subset of chronic rhinosinusitis patients, fungi may play a role). ${ }^{35}$ Furthermore, allergic and immunologic factors have also been shown to be associated with the development of rhinosinusitis; eg, perennial allergic rhinosinusitis is a documented predisposing condition for acute bacterial rhinosinusitis. ${ }^{39}$

The pathogenesis of rhinosinusitis, like that of allergic rhinitis, includes secretion of proinflammatory cytokines. In patients with acute rhinosinusitis, levels of inflammatory cytokines and total protein are significantly increased in nasal lavage fluid compared with healthy controls (Figure 2). ${ }^{40}$ Kinin levels have also been found to be markedly increased in the nasal secretions of patients with acute viral rhinosinusitis, and elevated levels of IL-1, IL-6, and IL- 8 have also been detected in the nasal secretions of these patients. ${ }^{4,41}$ Kinins can act on blood vessels to cause vascular leakage and/or engorgement, and they also stimulate afferent nerve fibers in the nasal mucosa, leading to hyperresponsiveness. ${ }^{4,42,43}$ In addition, TNF- $\alpha$ and other proinflammatory cytokines are elevated during the course of naturally acquired acute viral upper respiratory tract infection. ${ }^{44}$ Similar to allergic rhinitis, acute rhinosinusitis is also associated with significantly increased infiltration of inflammatory cells, including neutrophils and T cells, in the nasal epithelium and lamina propria. $^{45}$

The pathophysiology of chronic rhinosinusitis is not fully understood; however, the cytokine and mediator profile in this condition closely resembles the profile found in acute rhinosinusitis, with the exception of a small but significant increase in ECP. ${ }^{38}$ Nasal tissue samples taken from patients with chronic rhinosinusitis have been shown to have increased levels of leukotrienes $\mathrm{C}_{4}, \mathrm{D}_{4}$, and $\mathrm{E}_{4}$ and higher levels of markers of eosinophilic inflammation, such as ECP (Figure 3). ${ }^{46}$ In addition, a number of studies have reported that markers of atopy are more prevalent in populations with chronic rhinosinusitis. ${ }^{47-49}$ Although the role of allergy in chronic rhinosinusitis remains controversial, it has been postulated that swelling of the nasal mucosa in allergic rhinitis may restrict ventilation and obstruct sinus ostia, leading to mucus retention and infection. ${ }^{47}$ 

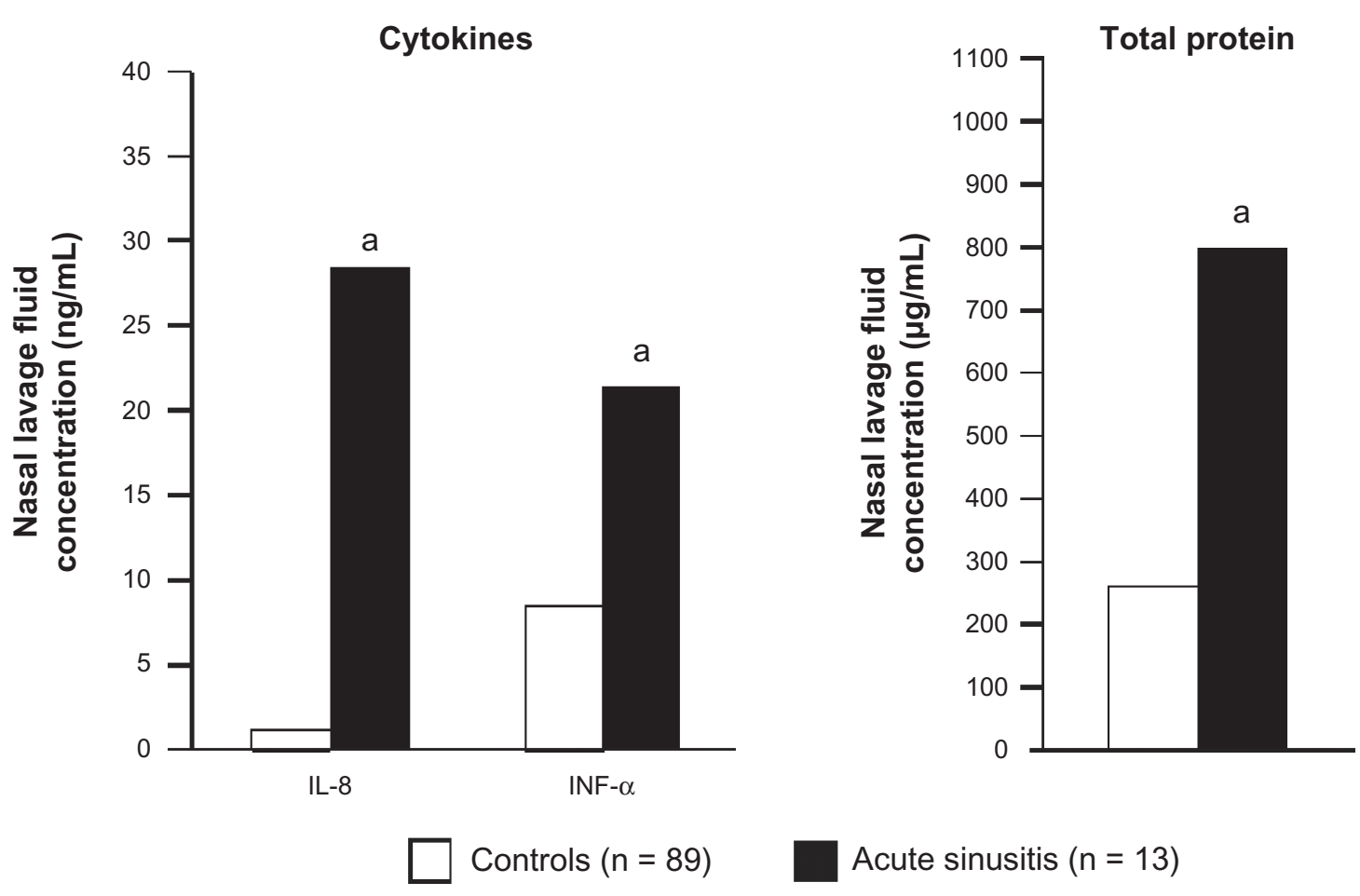

Figure 2 Increased levels of inflammatory cytokines and total protein are found in nasal lavage fluids from patients with acute rhinosinusitis compared with healthy controls. a $P \leq 0.0$ I I vs controls. Drawn from data of Repka-Ramirez et al. ${ }^{40}$

\section{Nasal polyposis}

Nasal polyposis is a chronic inflammatory disease of the upper airway characterized histologically by the infiltration of inflammatory cells, most notably eosinophils..$^{50}$ The cause or causes of nasal polyposis are not clear but may involve chronic infection, aspirin intolerance, alteration in aerodynamics with trapping of pollutants, epithelial disruptions, epithelial cell defects, or inhalant or food allergies. ${ }^{51,52}$ This condition may affect as much as $4 \%$ of the population, ${ }^{53}$ and its symptoms include nasal obstruction, nasal discharge, and impairment of sense of smell. ${ }^{47}$

Congestion in nasal polyposis is related to edema formation secondary to inflammatory processes similar to those described above for allergic rhinitis and rhinosinusitis. Numerous studies have demonstrated the presence of eosinophils and related mediators in patients with allergic or nonallergic nasal polyposis. These mediators include IL-4, IL-5, IL-6, IL-8, IL-10, TNF- $\alpha$, RANTES, GM-CSF, granulocyte colony-stimulating factor, ECP, eotaxin, and interferon (IFN)- $\gamma$ (Figure 4) ${ }^{54-57}$ Increased levels of metalloproteinases and destruction of extracellular matrix due to chronic inflammation are also thought to play a significant role in the pathobiology of nasal polyposis. ${ }^{58}$

The pattern of inflammatory markers in nasal polyposis differentiates this disease from chronic rhinosinusitis. T-cell response in CRS exhibits a Th1 pattern, in which interferon
(IFN)-g, transforming growth factor-b1 (50) and IL-3 (51) are key players. A Th2 pattern predominates in nasal polyposis, characterized by IgE production, infiltration of eosinophils and upregulation of cytokines and mediators, including IL-5, ECP and eotaxin, that drive eosinophil response. ${ }^{59}$ Staphylococcus aureus enterotoxins may play a role in the pathophysiology of NP. S. aureus colonization is higher in patients with NP compared to those with CRS, and IgE antibodies to $S$. aureus enterotoxins have been associated with higher levels of interleukin (IL)-5, eotaxin and eosinophil cationic protein (ECP). ${ }^{59}$ Nasal exposure to $S$. aureus enterotoxin B was shown to augment eosinophilic inflammation, IgE production, and cytokine production in mice, ${ }^{60}$ and recent data demonstrated that the stimulation of human NP tissue with $S$. aureus enterotoxin B significantly induced production of proinflammatory cytokines, with a shift toward a Th2 pattern of expression. ${ }^{61}$

\section{Structural problems}

Nasal congestion can also occur secondary to structural causes, such as septal deviation, choanal atresia, concha bullosa, cleft palate, adenoid hypertrophy, and neoplasia. ${ }^{34,62-66}$ The anterior nasal valve is the narrowest part of the airway, and inspiratory airflow through the nose can be compromised by the size of this nasal opening and the shape/structure of the nasal passages. Septal deviation may also cause impaired 
A

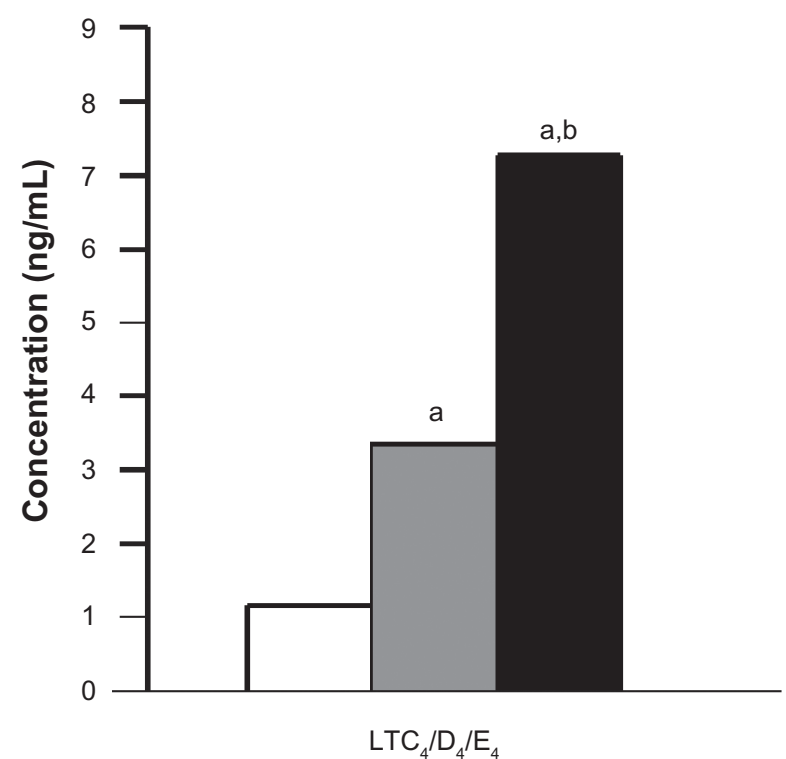

$\mathrm{LTC}_{4} / \mathrm{D}_{4} / \mathrm{E}_{4}$

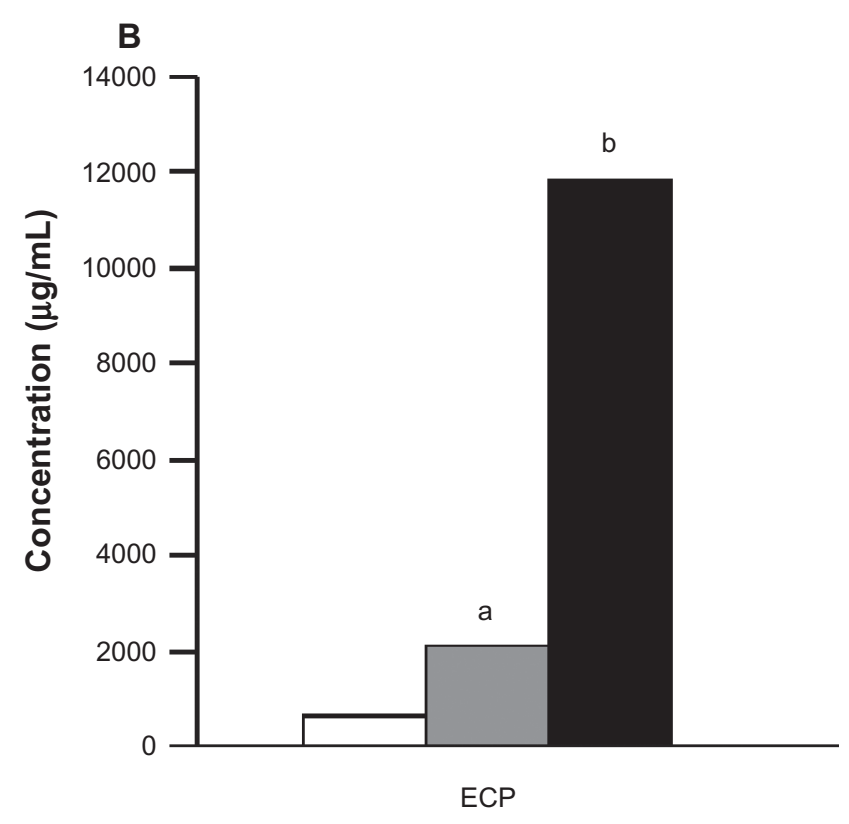

CRS
CRS-NP

Figure 3 Inflammation associated with chronic rhinosinusitis (CRS) and chronic rhinosinusitis with nasal polyps (CRS-NP). A) Levels of eicosanoid leukotrienes $\mathrm{C}_{4}$, $\mathrm{D}_{4}$, and $\mathrm{E}_{4}$ $\left(\mathrm{LTC}_{4} / \mathrm{D}_{4} / \mathrm{E}_{4}\right)$ were significantly higher in nasal tissue taken from CRS and CRS-NP patients compared with healthy controls. ${ }^{\mathrm{a}} \mathrm{P}<0.05$ vs controls. ${ }^{\mathrm{b}} \mathrm{P}<0.05$ vs $\mathrm{CRS}$. B) Levels of eosinophil cationic protein (ECP), a marker of eosinophilic inflammation, were significantly higher in nasal tissue taken from CRS and CRS-NP patients compared with healthy controls. ${ }^{a} P<0.05$ vs controls. ${ }^{b} P<0.02$ vs controls. Drawn from data of Pérez-Novo et al. ${ }^{46}$

airflow and the symptom/perception of nasal congestion. However, significant anatomic variance exists across individuals; anterior deflections affecting the nasal valve have the greatest impact on airflow, while those in the middle and inferior part of the nasal cavity have little effect on airflow resistance. ${ }^{67}$ Adenoid hypertrophy is another example of physical obstruction that can affect airflow, particularly in children, and it may also contribute to otitis media. ${ }^{63}$

The recumbent position can influence both the perception of nasal obstruction and objective measurements of nasal
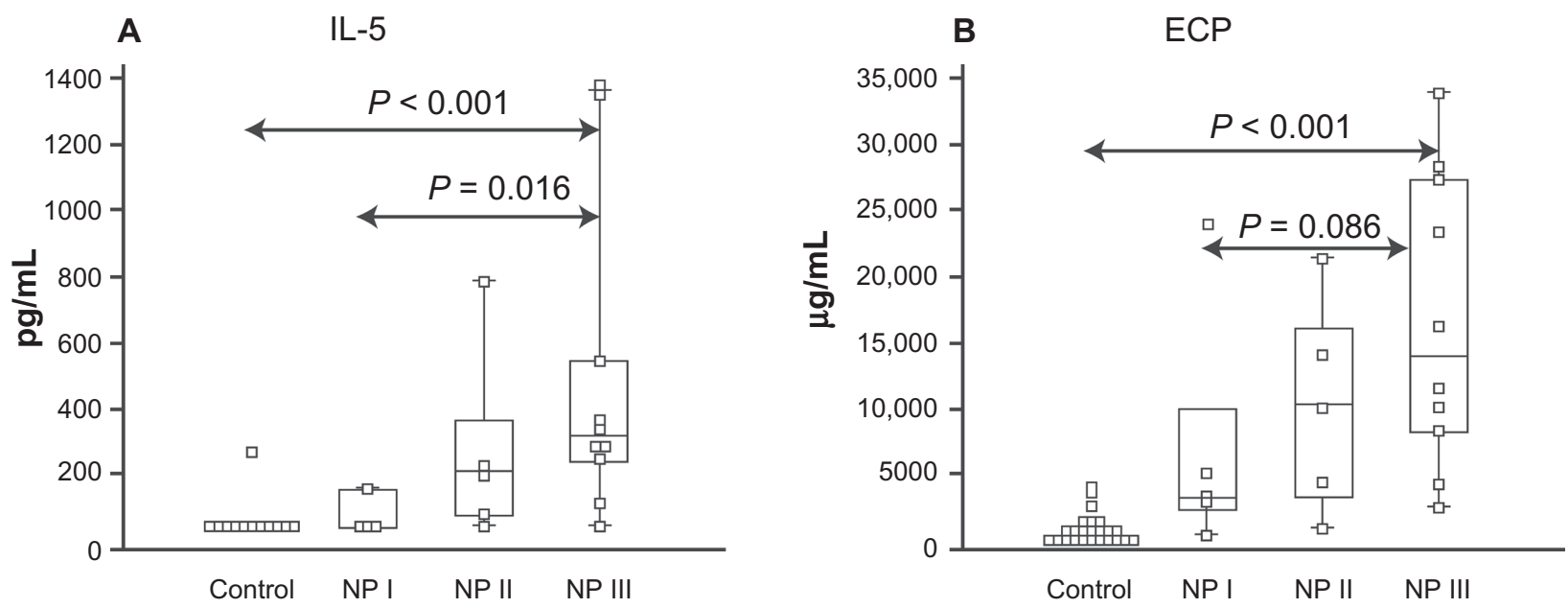

Figure 4 Inflammatory mediators and markers of nasal congestion in inferior turbinate tissue of control (those without polyps) and nasal polyposis (NP) patients. A) Patients with NP show significantly increased levels of interleukin (IL)-5, a proinflammatory cytokine, compared with controls. B) Patients with NP have increased levels of eosinophil cationic protein (ECP), a marker of eosinophilic inflammation, compared with controls. NP patients were grouped on the basis of the presence of specific immunoglobulin $E$ (IgE) antibodies in tissue: NP I, undetectable specific lgE; NP II, selected specific lgE; and NP III, multiclonal lgE. The box-and-whisker plot represents the median, the lower to upper quartile, and the minimum to the maximum value, excluding outside and far-out values, which are displayed as separate points. Adapted from J Allergy Clin Immunol, Vol 107, Bachert C, Gevaert P, Holtappels G, Johansson SG, van Cauwenberge P, Total and specific IgE in nasal polyps is related to local eosinophilic inflammation. Pages 607-6I4. ${ }^{57}$ Copyright (C) 200I, with permission from Elsevier. 
volume and nasal cross-sectional area in normal subjects, as well as in patients with rhinitis. ${ }^{68}$ It has been suggested that the nasal mucosa reaction to venous changes that alter local blood flow, secondary to compression of the neck veins or hydrostatic pressures, may give rise to this phenomenon. The perception of nasal obstruction induced by lying down seems to be greater in subjects with symptoms of rhinitis. ${ }^{68}$

Secondary inflammation may result from neurologic responses that involve a wide range of neurotransmitter systems. The nasal mucosa is invested with sensory, parasympathetic and sympathetic nerves, and they may all contribute to reflex activation of glands or neurogenic inflammation. Sensory nerves generate sensations, including pruritus, and provide the afferent limb for motor reflexes, such as sneezing. Parasympathetic and sympathetic reflexes can affect both glandular and vascular function in the nose. Neural function can be chronically upregulated in the presence of mucosal inflammation. This may lead to neural hyperresponsiveness and neurogenic inflammation, which is thought to result from the release of peptides (eg, substance P, calcitonin generelated peptide [CGRP], neurokinin A) from the peripheral terminals of nociceptive sensory nerve fibers. The molecular mechanisms underlying hyperresponsiveness are not fully understood but are thought to involve actions of neurotrophins on sensory afferents. ${ }^{43,69}$ The interplay of these molecules and the pathological processes they stimulate induce or exacerbate many typical upper respiratory symptoms, including congestion (Figure 5). ${ }^{43}$

\section{Modulation of sensory perception}

The sensory nerves of the nose arise from the olfactory nerve, as well as from the ophthalmic and maxillary branches of the trigeminal nerve. Nonolfactory sensory nerves consist of both myelinated and unmyelinated (primarily nociceptive) fibers. ${ }^{43}$ Physical and chemical stimuli, as well as endogenous biochemical products, can stimulate sensory afferents in the

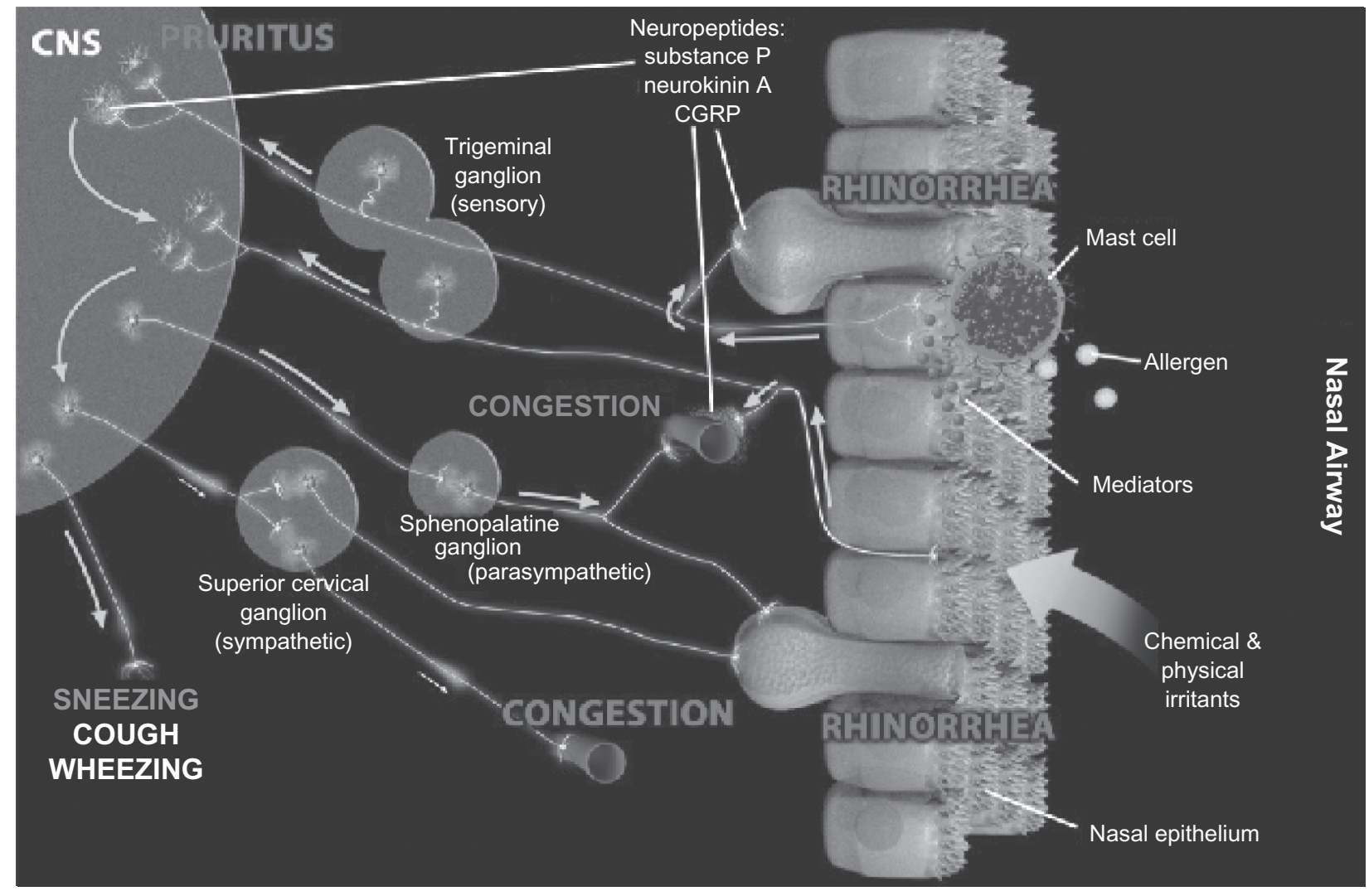

Figure 5 Generation of nasal symptoms through neural pathways. Sensory nerves can be stimulated by products of allergic reactions and by external physical and chemical irritants. Signals are transmitted to the central nervous system (CNS), where they can trigger sensations (pruritus) and can further travel through secondary synapses to activate efferent motor (sneezing) and autonomic neurons. Action potentials traveling through parasympathetic efferent nerves can lead to glandular activation and rhinorrhea, as well as to some vasodilatation. Suppression of sympathetic neural output, on the other hand, results in vasodilatation and nasal congestion. Antidromic stimulation of sensory nerves with release of tachykinins and other neuropeptides at the nasal mucosa contributes to symptom development with glandular activation, vasodilatation, and plasma extravasation. Neuropeptide release can also lead to leukocyte recruitment and activation. Collectively, events generated by the antidromic stimulation of sensory nerves constitute the phenomenon of "neurogenic inflammation". Reprinted from J Allergy Clin Immunol, Vol I I 8, Sarin S, Undem B, Sanico A, Togias A, The role of the nervous system in rhinitis, Pages 999-1016, Copyright 2006, with permission from American Academy of Allergy, Asthma and Immunology. ${ }^{43}$ 
nasal mucosa to carry sensations (eg, pruritus) to the central nervous system and also activate reflexes (eg, sneezing). ${ }^{43}$ It should be noted that symptoms typical of rhinitis can be produced through neural mechanisms without any demonstrable mucosal abnormality. ${ }^{43}$ In addition, mentholated vapors can influence the perception of relief from congestion without actually altering airflow. This effect is thought to be due to activation of cold receptors by menthol, and this cool sensation creates the impression of increased airflow. ${ }^{70}$ Conversely, patients with complete turbinectomy ("empty nose") may still complain of the perception of nasal congestion. ${ }^{66,71}$ The importance of events initiated by the nervous system is further underscored by the many patients with perennial nonallergic rhinitis who complain of nasal congestion in the absence of any demonstrable abnormalities in the mucosa. ${ }^{72}$

\section{Role of specific neural pathways in rhinitis symptoms}

Specific symptoms of rhinitis are mediated by the actions of distinct neural pathways. Sensory axons can be classified according to size, conduction velocity, the neurotransmitters they release, and the different types of stimuli to which they are sensitive. Small unmyelinated fibers (C fibers) conduct action potentials slowly and are generally responsive to noxious mechanical and chemical stimuli. Thinly myelinated A $\delta$ fibers are also nociceptors. Larger myelinated A $\beta$ fibers have more rapid conduction velocities and may convey nonnociceptive information. Pruritus is a tactile sensation that is conveyed to the central nervous system via trigeminal fibers that have their cell bodies in the trigeminal ganglion. ${ }^{43,69}$

Trigeminal neuronal activation caused by mast cell mediators may also contribute to sneezing and itching. Calcitonin gene-related peptide (CGRP), a potent vasodilator that may play a role in congestion, is also associated with trigeminal activation and is increased in nasal lavage fluids following allergen challenge. Support for the role of trigeminal activation in the development of AR symptoms is seen in a recent study in which inhalation of $\mathrm{CO}_{2}$, a known inhibitor of both neuronal activation and CGRP release, significantly improved nasal allergy symptoms, including congestion. ${ }^{73}$

Abnormalities in parasympathetic reflex arcs may also contribute to the development of rhinorrhea and congestion. It has been suggested that vasomotor, idiopathic, or "irritant" rhinitis may result from increased sensitivity of afferent fibers to irritant stimuli and/or augmented glandular responses to activation by parasympathetic axons. ${ }^{69}$

Increased understanding of the neurotransmitters and other modulators released by different primary afferents has led to the realization that these neurons can also be classified on the basis of the molecules they use to communicate with other cells. Primary afferents can also be differentiated on the basis of the specific receptors they express and thus the substances to which they are sensitive. A small subset of $\mathrm{C}$ fibers that express histamine $\mathrm{H}_{1}$, and perhaps also $\mathrm{H}_{4}$, receptors convey information that gives rise to the sensation of itch. ${ }^{74,75}$ Another subset of $\mathrm{C}$ fibers expresses transient receptor potential vanilloid-1 (TRPV1) receptors. Primary afferents expressing these receptors are thought to be involved in detection of painful heat stimuli. ${ }^{76}$ These receptors are also involved in the development of thermal hyperalgesia that may occur secondary to inflammation. ${ }^{77}$ In addition to sensing thermal stimuli, primary afferents with TRPV receptors also convey information about mechanical stimuli and changes in local osmolarity. ${ }^{78}$

A growing body of evidence has indicated that the neurotransmitter phenotypes of primary afferent neurons are highly plastic and may change rapidly as a function of exposure to inflammatory stimuli. This inflammatory neuroplasticity is the consequence of a combination of activity-dependent changes in the neurons and specific molecules that initiate particular signal transduction pathways. ${ }^{79}$ An inflammationinduced release of mediators can change the properties of primary sensory neurons, producing alterations in sensitivity and changes in transmitter phenotypes. For example, inflammation results in a nerve growth factor-dependent increase in substance $\mathrm{P}$ expression in $\mathrm{C}$ fibers and novel expression of this neuropeptide in some large $A \beta$ fibers, which do not normally contain this peptide. ${ }^{79}$ Alterations of this type may contribute to the sensation of congestion in the absence of impaired breathing or blocked nasal passages. This suggestion is supported by the observation that nasal responsiveness to histamine and capsaicin (a highly specific stimulus for $\mathrm{C}$ fibers) is increased in subjects with allergic rhinitis. ${ }^{80}$ It has also been noted that patient perception of idiopathic rhinitis improves with long-term exposure to capsaicin, an agent that desensitizes nerves but has no effect on inflammatory mediators. These data support the view that alterations in sensory processing may play a role in the pathophysiology of congestion in some cases. ${ }^{81,82}$

\section{Summary}

Nasal obstruction or congestion is one of the most common symptoms encountered in primary care and specialist clinics, and it is the symptom that is most bothersome to patients. Mucosal inflammation is the primary pathophysiological mechanism leading to congestion in common upper 
respiratory diseases, such as allergic rhinitis, rhinosinusitis, and nasal polyposis. Mucosal inflammation in these conditions is responsible for many of the distinct and interrelated factors that contribute to congestion, including increased venous engorgement, elevated nasal secretions, and tissue swelling/edema. In addition, mechanical and structural features of the sinonasal passages (eg, septal deviation, choanal atresia, concha bullosa and adenoid hypertrophy) can result in blockage/obstruction/congestion. Importantly, neurogenic mechanisms also contribute significantly to the pathophysiological changes underlying nasal congestion, and abnormal primary afferent signaling may give rise to the sensation of congestion even in the absence of inflammation and impaired airflow. A greater understanding of the pathophysiological mechanisms underlying congestion, in particular the mucosal inflammation associated with common conditions such as allergic rhinitis and rhinosinusitis, has the potential to help clinicians and researchers optimize treatment with existing therapies and develop new treatments for these conditions.

\section{Acknowledgments}

Editorial assistance was provided by Henry Hamilton, $\mathrm{PhD}$, former employee of Health Science Communications, Inc., and Joyce O'Connor, MS of Health Science Communications, Inc. This assistance was funded by Schering-Plough Corporation, now Merck \& Co., Whitehouse Station, NJ, USA.

\section{Disclosures}

Dr Naclerio: grant support from Merck, GlaxoSmithKline, Schering-Plough Corporation, now Merck \& Co., Whitehouse Station, NJ, USA.

Dr Bachert: study funding from Schering-Plough Corporation, now Merck \& Co., Whitehouse Station, NJ, USA, lecturer for Schering-Plough Corporation, now Merck \& Co., Whitehouse Station, NJ, USA.

Dr Baraniuk: none.

\section{References}

1. Corey JP, Houser SM, Ng BA. Nasal congestion: a review of its etiology, evaluation, and treatment. Ear Nose Throat J. 2000; 79(9):690-698.

2. Wang DY, Raza MT, Gordon BR. Control of nasal obstruction in perennial allergic rhinitis. Curr Opin Allergy Clin Immunol. 2004;4(3): 165-170.

3. Romero FA, Casale TB. Correlation between objective and subjective measures of nasal congestion in a nasal allergen challenge model. J Allergy Clin Immunol. 2009;123:S204-S204. Abstract 784.

4. Proud D, Naclerio RM, Gwaltney JM, Hendley JO. Kinins are generated in nasal secretions during natural rhinovirus colds. $J$ Infect Dis. 1990;161(1):120-123.
5. Corboz MR, Mutter JC, Rivelli MA, et al. Alpha2-adrenoceptor agonists as nasal decongestants. Pulm Pharmacol Ther. 2007;20(2):149-156.

6. Staevska MT, Baraniuk JN. Differential diagnosis of persistent nonallergic rhinitis and rhinosinusitis syndromes. Clin Allergy Immunol. 2007;19:35-53.

7. Ramey JT, Bailen E, Lockey RF. Rhinitis medicamentosa. J Investig Allergol Clin Immunol. 2006;16(3):148-155.

8. Graf P. Rhinitis medicamentosa: aspects of pathophysiology and treatment. Allergy. 1997;52(40 Suppl):28-34.

9. Bousquet J, Khaltaev N, Cruz AA, et al. Allergic Rhinitis and its Impact on Asthma (ARIA) 2008 update (in collaboration with the World Health Organization, GA²LEN and AllerGen). Allergy. 2008;63(Suppl 86): $8-160$.

10. Meltzer EO, Blaiss MS, Derebery MJ, et al. Burden of allergic rhinitis: results from the Pediatric Allergies in America survey. J Allergy Clin Immunol. 2009;124(3):S43-S70.

11. Asher M, Montefort S, Bjorksten B, et al; and the ISAAC Phase Three Study Group. Worldwide trends in the prevalence of symptoms of asthma, allergic rhinoconjunctivitis, and eczema in childhood: ISAAC Phases One and Three repeat multicountry cross-sectional surveys. Lancet. 2006;368:733-743.

12. Nathan RA. Pharmacotherapy for allergic rhinitis: a critical review of leukotriene receptor antagonists compared with other treatments. Ann Allergy Asthma Immunol. 2003;90(2):182-190.

13. Pearlman DS. Pathophysiology of the inflammatory response. JAllergy Clin Immunol. 1999;104(4 Pt 1):S132-S137.

14. White M. Mediators of inflammation and the inflammatory process. J Allergy Clin Immunol. 1999;10(3 Pt 2):S378-S381.

15. Quraishi SA, Davies MJ, Craig TJ. Inflammatory responses in allergic rhinitis: traditional approaches and novel treatment strategies. $J \mathrm{Am}$ Osteopath Assoc. 2004;104(Suppl 5):S7-S15.

16. Bascom R, Pipkorn U, Lichtenstein LM, Naclerio RM. The influx of inflammatory cells into nasal washings during the late response to antigen challenge. Effect of systemic steroid pretreatment. Am Rev Respir Dis. 1988;138(2):406-412.

17. Bascom R, Wachs M, Naclerio RM, Pipkorn U, Galli SJ, Lichtenstein LM. Basophil influx occurs after nasal antigen challenge: effects of topical corticosteroid pretreatment. J Allergy Clin Immunol. 1988;81(3): $580-589$.

18. Minshall E, Ghaffar O, Cameron L, et al. Assessment by nasal biopsy of long-term use of mometasone furoate aqueous nasal spray (Nasonex) in the treatment of perennial rhinitis. Otolaryngol Head Neck Surg. 1998;118(5):648-654.

19. Bachert C, Wagenmann M, Holtappels G. Cytokines and adhesion molecules in allergic rhinitis. Am J Rhinol. 1998;12(1):3-8.

20. Gelfand EW. Inflammatory mediators in allergic rhinitis. J Allergy Clin Immunol. 2004;114(5 Supp1):S135-S138.

21. Wang D, Clement P, Smitz J, Derde MP. Concentrations of chemical mediators in nasal secretions of patients with hay fever during natural allergen exposure. Acta Otolaryngol. 1994;114(5):552-555.

22. Creticos PS, Peters SP, Adkinson NF Jr, Naclerio RM, Hayes EC, Norman PS. Peptide leukotriene release after antigen challenge in patients sensitive to ragweed. $N$ Engl J Med. 1984; 310(25):1626-1630.

23. Okuda M, Watase T, Mezawa A, Liu CM. The role of leukotriene D4 in allergic rhinitis. Ann Allergy. 1988;60(6):537-540.

24. Kishi Y, Nakano Y, Jiang S, et al. Participation in cysteinyl leukotrienes and thromboxane A2 in nasal congestion model in Brown Norway rats. Int Immunopharmacol. 2007;7:1483-1487.

25. Shirasaki H, Kikuchi M, Seki N, Kanaizumi E, Watanabe K, Himi T. Expression and localization of the thromboxane A2 receptor in human nasal mucosa. Prostaglandins Leukot Essent Fatty Acids. 2007;76(6): 315-320.

26. Okano M, Fujiwara T, Sugata Y, et al. Presence and characterization of prostaglandin D2-related molecules in nasal mucosa of patients with allergic rhinitis. Am J Rhinol. 2006; 20(3):342-348. 
27. Cameron HL, Yang PC, Perdue MH. Glucagon-like petide-2enhanced barrier function reduces pathophysiology in a model of food allergy. Am J Physiol Gastrointest Liver Physiol. 2003;284(6): G905-G912.

28. Ciprandi G, Cirillo I, Vizzaccaro A, Milanese M, Tosca MA. Nasal obstruction in patients with seasonal allergic rhinitis: relationships between allergic inflammation and nasal airflow. Int Arch Allergy Immunol. 2004;134(1):34-40.

29. Wachs M, Proud D, Lichtenstein LM, Kagey-Sobotka A, Norman PS, Naclerio RM. Observations on the pathogenesis of nasal priming. J Allergy Clin Immunol. 1989;84(4 Pt 1):492-501.

30. Howarth PH, Salagean M, Dokic D. Allergic rhinitis: not purely a histamine-related disease. Allergy. 2000;55(Suppl 64):7-16.

31. Simon HU. Molecular mechanisms of defective eosinophil apoptosis in diseases associated with eosinophilia. Int Arch Allergy Immunol. 1997;113(1-3):206-208.

32. Widegren H, Erjefalt J, Korsgren M, et al. Effects of intranasal TNFalpha on granulocyte recruitment and activity in healthy subjects and patients with allergic rhinitis. Respir Res. 2008;9:15.

33. Howarth $\mathrm{PH}$. ABC of allergies. Pathogenic mechanisms: a rational basis for treatment. BMJ. 1998;316(7133):758-761.

34. Wallace DV, Dykewicz, Bernstein DI, et al; for the Joint Task Force on Practice Parameter for Allergy and Immunology. The diagnosis and management of rhinitis: an updated practice parameter. J Allergy Clin Immunol. 2008;122(Suppl 2):S1-S84.

35. Meltzer EO, Hamilos DL, Hadley JA, et al. Rhinosinusitis: establishing definitions for clinical research and patient care. Otolaryngol Head Neck Surg. 2004;131(6 Suppl):S1-S62.

36. Kaliner MA, Osguthorpe JD, Fireman P, et al. Sinusitis: bench to bedside. Current findings, future directions. Otolaryngol Head Neck Surg. 1997;116(6 Pt 2):S1-S20.

37. Gwaltney JM. Clinical significance and pathogenesis of viral respiratory infections. Am J Med. 2002;112(Suppl 6A):13S-18S.

38. European Academy of Allergology and Clinical Immunology. European position paper on rhinosinusitis and nasal polyps. Rhinol Suppl. 2005; (Suppl 18):1-87.

39. Berrettini S, Carabelli A, Sellari-Franceschini S, et al. Perennial allergic rhinitis and chronic sinusitis: correlation with rhinologic risk factors. Allergy. 1999;54(3):242-248.

40. Repka-Ramirez S, Naranch K, Park YJ, Clauw D, Baraniuk JN. Cytokines in nasal lavage fluids from acute sinusitis, allergic rhinitis, and chronic fatigue syndrome subjects. Allergy Asthma Proc. 2002;23(3):185-190.

41. Röseler S, Holtappels G, Wagenmann M, Bachert C. Elevated levels of interleukins IL-1 beta, IL-6 and IL-8 in naturally acquired viral rhinitis. Eur Arch Otorhinolaryngol. 1995;252(Suppl 1):S61-S63.

42. Renné T, Schuh K, Muller-Esterl W. Local bradykinin formation is controlled by glycosaminoglycans. J Immunol. 2005;175(5):3377-3385.

43. Sarin S, Undem B, Sanico A, Togias A. The role of the nervous system in rhinitis. J Allergy Clin Immunol. 2006;118(5):999-1016.

44. Bachert C, van Kempen MJ, Hopken K, Holtappels G, Wagenmann M. Elevated levels of myeloperoxidase, pro-inflammatory cytokines and chemokines in naturally acquired upper respiratory tract infections. Eur Arch Otorhinolaryngol. 2001;258(8):406-412.

45. Berger G, Kattan A, Bernheim J, Ophir D, Finkelstein Y. Acute sinusitis: a histopathological and immunohistochemical study. Laryngoscope. 2000;110(12):2089-2094.

46. Pérez-Novo CA, Claeys C, Van Cauwenberge P, Bachert C. Expression of eicosanoid receptors subtypes and eosinophilic inflammation: implication on chronic rhinosinusitis. Respir Res. 2006;7:75.

47. Fokkens W, Lund V, Bachert C, et al. EAACI position paper on rhinosinusitis and nasal polyps executive summary. Allergy. 2005;60(5):583-601.

48. Savolainen S. Allergy in patients with acute maxillary sinusitis. Allergy. 1989;44(2):116-122.

49. Emanuel IA, Shah SB. Chronic rhinosinusitis: allergy and sinus computed tomography relationships. Otolaryngol Head Neck Surg. 2000;123(6):687-691.
50. Mygind N, Dahl R, Bachert C. Nasal polyposis, eosinophil dominated inflammation, and allergy. Thorax. 2000;55(Suppl 2):S79-S83.

51. Pawankar R. Nasal polyposis: an update: editorial review. Curr Opin Allergy Clin Immunol. 2003;3(1):1-6.

52. Stjarne P, Mosges R, Jorissen M, et al. A randomized controlled trial of mometasone furoate nasal spray for the treatment of nasal polyposis. Arch Otolaryngol Head Neck Surg. 2006;132(2):179-185.

53. Hedman J, Kaprio J, Poussa T, Nieminen MM. Prevalence of asthma, aspirin intolerance, nasal polyposis and chronic obstructive pulmonary disease in a population-based study. Int J Epidemiol. 1999;28(4): 717-722.

54. Bachert C, Gevaert P, Holtappels G, Cuvelier C, van Cauwenberge P. Nasal polyposis: from cytokines to growth. Am J Rhinol. 2000;14(5): 279-290.

55. Bachert C, Gevaert P, Holtappels G, van Cauwenberge P. Mediators in nasal polyposis. Curr Allergy Asthma Rep. 2002;2(6):481-487.

56. Gevaert P, Bachert C, Holtappels G, Novo CP, Van der Heyden J, Fransen L. Enhanced soluble interleukin-5 receptor alpha expression in nasal polyposis. Allergy. 2003;58(5):371-379.

57. Bachert C, Gevaert P, Holtappels G, Johansson SG, van Cauwenberge P. Total and specific IgE in nasal polyps is related to local eosinophilic inflammation. J Allergy Clin Immunol. 2001;107(4):607-614.

58. Watelet JB, Bachert C, Claeys C, Van Cauwenberge P. Matrix metalloproteinases MMP-7, MMP-9 and their tissue inhibitor TIMP-1: expression in chronic sinusitis vs nasal polyposis. Allergy. 2004;59(1):54-60.

59. Bachert C, Zhang N, Patou J, van Zele T, Gevaert P. Role of staphylococcal superantigens in upper airway disease. Curr Opin Allergy Clin Immunol. 2008;8(1):34-38.

60. Okano M, Fujiwara T, Haruna T, et al. Prostaglandin E2 suppresses staphylococcal enterotoxin-induced eosinophilia-associated cellular responses dominantly through an E-prostanoid 2-mediated pathway in nasal polyps. J Allergy Clin Immunol. 2009;123(4):868-874.

61. Patou J, Gevaert P, Van Zele T, Holtappels G, van Cauwenberge P, Bachert C. Staphylococcus aureus enterotoxin B, protein A, and lipoteichoic acid stimulations in nasal polyps. J Allergy Clin Immunol. 2008;121(1):110-115.

62. Farmer SE, Eccles R. Chronic inferior turbinate enlargement and the implications for surgical intervention. Rhinology. 2006; 44(4):234-238.

63. Wright ED, Pearl AJ, Manoukian JJ. Laterally hypertrophic adenoids as a contributing factor in otitis media. Int J Pediatr Otorhinolaryngol. 1998;45(3):207-214.

64. Kemker B, Liu X, Gungor A, Moinuddin R, Corey JP. Effect of nasal surgery on the nasal cavity as determined by acoustic rhinometry. Otolaryngol Head Neck Surg. 1999;121(5):567-571.

65. Bar-Sela S, Levy M, Westin JB, Laster R, Richter ED. Medical findings in nickel-cadmium battery workers. Isr J Med Sci. 1992;28(8-9): 578-583.

66. Warwick-Brown NP, Marks NJ. Turbinate surgery: how effective is it? A long-term assessment. ORL J Otorhinolaryngol Relat Spec. 1987;49(6):314-320.

67. Cole P, Chaban R, Naito K, Oprysk D. The obstructive nasal septum. Effect of simulated deviations on nasal airflow resistance. Arch Otolaryngol Head Neck Surg. 1988;114(4):410-412.

68. Roithmann R, Demeneghi P, Faggiano R, Cury A. Effects of posture change on nasal patency. Rev Bras Otorrinolaringol (Engl Ed). 2005;71(4):478-484

69. Tai CF, Baraniuk JN. Upper airway neurogenic mechanisms. Curr Opin Allergy Clin Immunol. 2002;2(1):11-19.

70. Eccles R. Menthol: effects on nasal sensation of airflow and the drive to breathe. Curr Allergy Asthma Rep. 2003;3(3):210-214.

71. Moore GF, Freeman TJ, Ogren FP, Yonkers AJ. Extended follow-up of total inferior turbinate resection for relief of chronic nasal obstruction. Laryngoscope. 1985;95(9 Pt 1):1095-1099.

72. Enberg RN. Perennial nonallergic rhinitis: a retrospective review. Ann Allergy. 1989;63(6 Pt 1):513-516. 
73. Casale TB, Romero FA, Spierings ELH, et al. Intranasal noninhaled carbon dioxide for the symptomatic treatment of seasonal allergic rhinitis. J Allergy Clin Immunol. 2008;121(1):105-109.

74. Rees J, Murray CS. Itching for progress. Clin Exp Dermatol. 2005;30(5):471-473.

75. Tai CF, Baraniuk JN. A tale of two neurons in the upper airways: pain versus itch. Curr Allergy Asthma Rep. 2003;3(3):215-220.

76. Steenland HW, Ko SW, Wu LJ, Zhuo M. Hot receptors in the brain. Mol Pain. 2006;2:34.

77. Liedtke W, Kim C. Functionality of the TRPV subfamily of TRP ion channels: add mechano-TRP and osmo-TRP to the lexicon! Cell Mol Life Sci. 2005;62(24):2985-3001.

78. Montell C. Physiology, phylogeny, and functions of the TRP superfamily of cation channels. Sci STKE. 2001;2001(90):RE1.
79. Woolf CJ, Costigan M. Transcriptional and posttranslational plasticity and the generation of inflammatory pain. Proc Natl Acad Sci U S A. 1999;96(14):7723-7730.

80. Togias A. Unique mechanistic features of allergic rhinitis. J Allergy Clin Immunol. 2000;105(6 Pt 2):S599-S604.

81. Blom HM, Severijnen LA, Van Rijswijk JB, Mulder PG, Van Wijk RG, Fokkens WJ. The long-term effects of capsaicin aqueous spray on the nasal mucosa. Clin Exp Allergy. 1998;28(11):1351-1358.

82. Blom HM, Van Rijswijk JB, Garrelds IM, Mulder PG, Timmermans T, Gerth van Wijk R. Intranasal capsaicin is efficacious in non-allergic, non-infectious perennial rhinitis. A placebo-controlled study. Clin Exp Allergy. 1997;27(7):796-801.
International Journal of General Medicine

\section{Publish your work in this journal}

The International Journal of General Medicine is an international, peer-reviewed open-access journal that focuses on general and internal medicine, pathogenesis, epidemiology, diagnosis, monitoring and treatment protocols. The journal is characterized by the rapid reporting of reviews, original research and clinical studies across all disease areas.

\section{Dovepress}

A key focus is the elucidation of disease processes and management protocols resulting in improved outcomes for the patient.The manuscript management system is completely online and includes a very quick and fair peer-review system. Visit http://www.dovepress.com/ testimonials.php to read real quotes from published authors.

Submit your manuscript here: http://www.dovepress.com/international-journal-of-general-medicine-journal 